\title{
DINÂMICA DA NUTRIC̣ÃO DE METYNNIS CF. ROOSEVELTI EIGENMANN (CHARACIDAE, MYLEINAE), DA LAGOA REDONDA, NÍZIA FLORESTA, RIO GRANDE DO NORTE, BRASIL
}

\author{
Hélio de Castro Bezerra Gurgel ${ }^{1}$ \\ Geraldo Barbieri ${ }^{2}$ \\ Marcos de Afonso Martins ${ }^{2}$
}

\begin{abstract}
THE DYNAMICS OF NUTRITION IN METYNNIS CF, ROOSEVELTI EIGENMANN (Characidae, Myl.einae), from lagoa Rhionda, nizia Floresta, Rio Grande DO NORTE, BRAZIL. The time of full stomach repletion and fat condition was determined through an analysis of the average stomach repletion index, condition factor and relative frequency of repletion for different periods of the year. Condition factor was influenced by weight gain in the stomaches, main from April to June. KEY WORDS. Metynnis, fat condition, stomach repletion index
\end{abstract}

O Brasil, detentor do maior potencial de águas continentais no continente sul-americano, possui uma das mais ricas ictiofaunas do mundo, apesar de pouco conhecida sob vários aspectos biológicos BRITSKI et. al (1984). Neste contexto BRITSKI (1978) menciona a importância da realização de estudos de recenseamento das espécies e de seus aspectos biológicos, em razão do incipiente conhecimento que se tem atualmente de peixes de água doce da América do Sul, quando comparada ao de certas áreas e, em áreas sujeitas a alterações ambientais, corre o risco de ser modificada, tornar-se rara ou mesmo de se extinguir.

Aspectos da biologia dos organismos aquáticos devem ser estudados para possibilitar conhecimento sobre a estrutura das populações, suas potencialidades de reposição, tais como mecanismos de reprodução e sobrevivência, hábitos alimentares e migratórios, além da velocidade de crescimento. A necessidade de obter-se essas informações torna-se cada vez mais premente, pois no Brasil, tem ocorrido um acentuado desenvolvimento tecnológico da pesca que, sem o acompanhamento de orientação pesqueira, tem trazido problemas de sobrepesca para as populações naturais (GULLAND 1971; VAZZOLER \& VAZZOLER 1965).

No presente estudo analisam-se aspectos da dinâmica da nutrição de Metynnis cf. roosevelti Eigenmann, 1915, da Lagoa Redonda, Nízia Floresta, Rio Grande do Norte.

1) Departamento de Botâniea, Ecologia e Zoologia, Centro de Bicciências, Universidade Federal do Rio Grande do Norte, Campus Universitário, 59072-970 Natal, Rio Grande do Norte, Brasil.

2) Departamento de Hidrobiologia, Universidade Federal de São Carlos, Caixa Postal 676, 13565-905 São Carlos, São Paulo, Brasil. 


\section{MATERIAL E MÉTODOS}

Exemplares de Metynnis cf. roosevelti foram capturados quinzenalmente durante o período de abril de 1987 a março de 1988, correspondendo a um ciclo sazonal, com o auxilio de redes e tarrafas com diferentes tamanhos de malha, num total de 2138 exemplares, sendo 1112 fềmeas e 1026 machos, na Lagoa Redonda, Nízia Floresta, Rio Grande do norte $\left(4^{\circ} 51^{\prime} 54^{\prime \prime}\right.$ e $68^{\circ} 58^{\prime} 18^{\prime \prime}$ LS e $34^{\circ} 57^{\prime} 08^{\prime \prime}$ e $\left.38^{\circ} 35^{\circ} 12^{\prime \prime} \mathrm{WG}\right)$.

Para cada indivíduo coletado, foram consideradas as seguintes variáveis biométricas: comprimento total (Lt) em centímetros, peso total $(\mathrm{Wt})$ e peso de estômago (We) em gramas. Os estádios de repleção foram considerados em relação à quantidade de alimento presente: vazio (I), parcialmente cheio (II) e cheio (III).

Aplicando-se a metodologia descrita em SANTOS (1978) foram estabelecidos: grau médio de repleção $(\mathrm{Gr})$, índice médio de repleção (Ir), relação peso total/comprimento total e o fator de condição.

\section{RESULTADOS}

Pode-se constatar pela análise das figuras $\mathrm{B}$ e $2 \mathrm{~B}$ que nos meses de abril/maio, encontram-se os menores valores do índice médio de repleção para ambos os sexos. Os estômagos neste período encontram-se praticamente nos estádios I e II (vazio e semi cheio) com predominância neste último (Figs 1D, 2D).

Observa-se que os valores médios mais elevados do grau médio de repleção, para as fềmeas e para os machos, são registrados nos bimestres junho/julho quando estes começam a se declinar até agosto/setembro, reiniciando-se o aumento em outubro/novembro (Figs 1C, 2C).

Os valores máximos do fator de condição constatados no bimestre junho/julho, aliados aos registros de maiores freqüências do índice médio de repleção, do grau médio de repleção e do estádio de repleção III (estômagos cheios) neste bimestre, revelam que a atividade alimentar da espécie atinge seu pico de máxima neste período (Figs 1A, 2A).

\section{DISCUSSÃO E CONCLUSÕES}

Dentre os aspectos da alimentação de Metynnis cf. roosevelti, analisados neste trabatho, os graus de repleção de estômagos (I, II e III), bem como os valores médios do grau médio de repleção, índice de repleção e do fator de condição, proporcionaram o conhecimento de alguns aspectos da dinâmica alimentar da espécie.

$\mathrm{O}$ índice de repleção caracterizado por ser um caráter quantitativo, define com mais segurança qual a época em que o peixe se apresenta em melhores condições alimentares (BARBIERI 1981). Na presente investigação, ohserva-se que os maiores valores do índice médio de repleção são encontrados no bimestre junho/julho, isto é, no período que antecede à reprodução (GURGEL 1992). Assim esses resultados, além de sugerirem que nessa época os peixes apresentam 


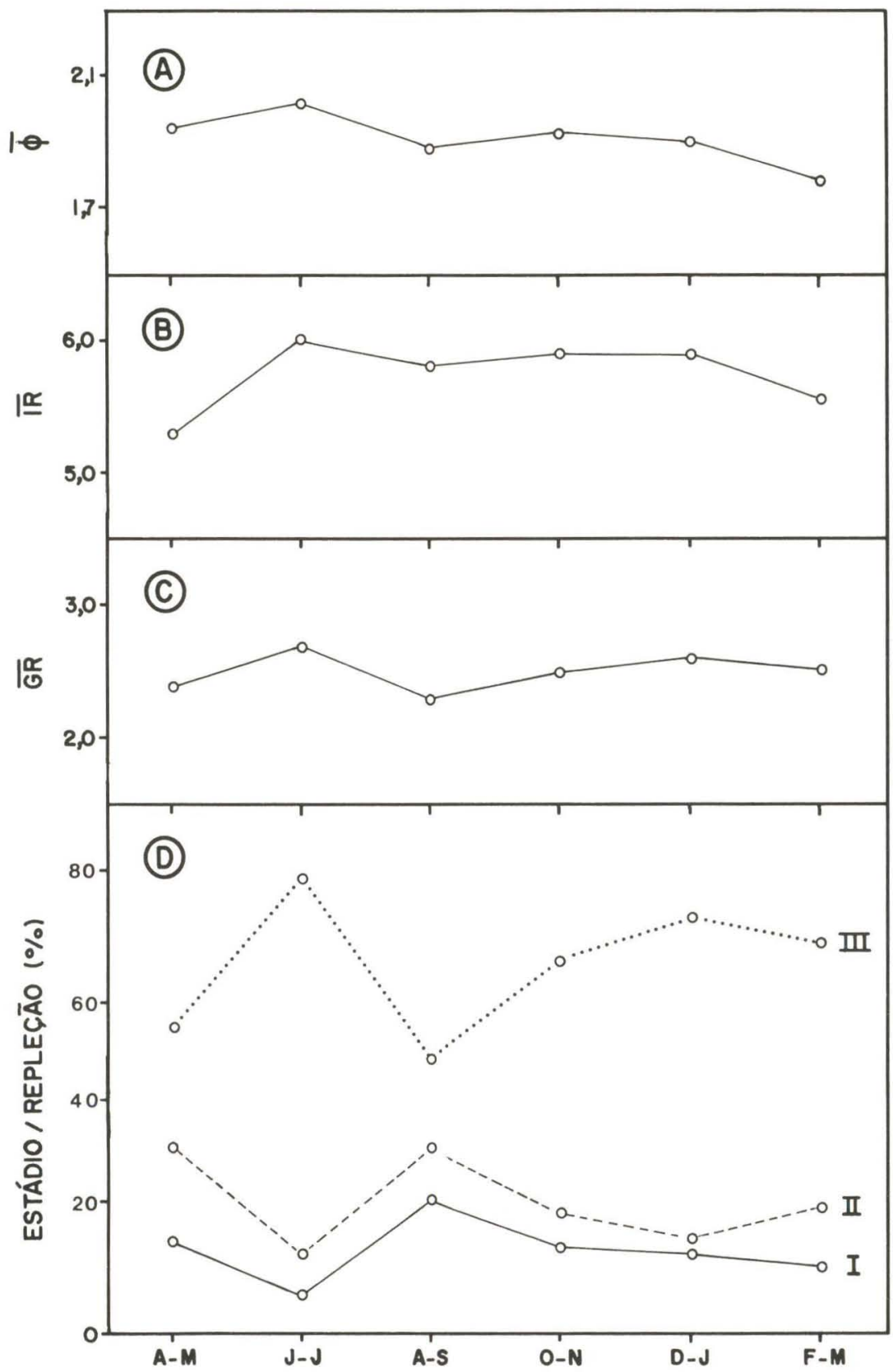

Fig. 1. Variaçào do fator de condiçâo, indice de repleçâo, grau médio de repleçáo e da freqüêneia relativa dos graus médios de repleção de fềmeas de Metynnis of. roosevelti, durante o período de estudo.

Revta bras. Zool. 11 (2): 325 - 330, 1994 


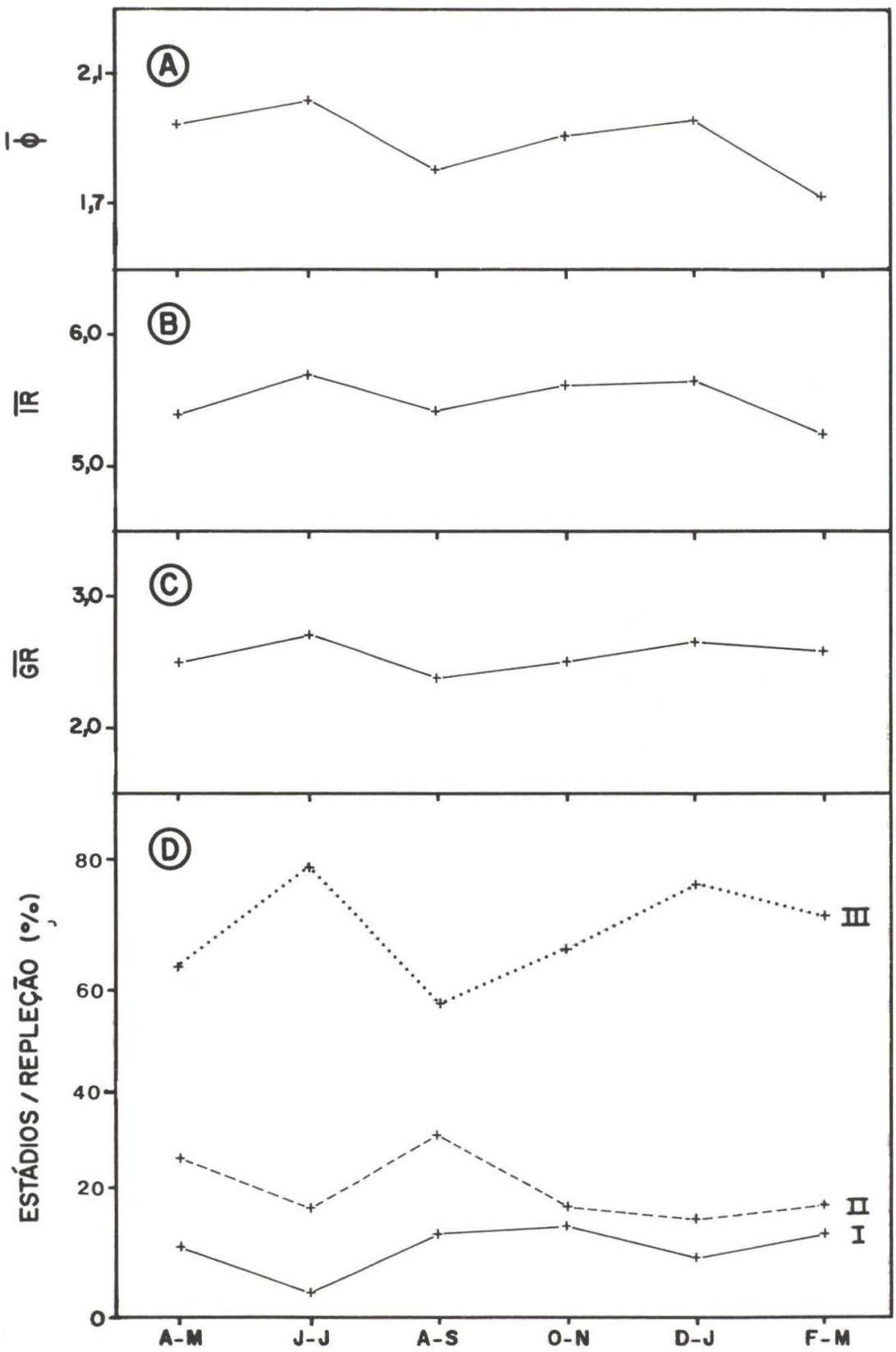

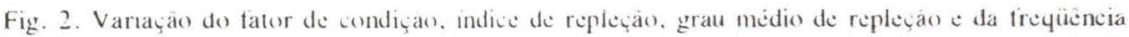
relativa dos graus médios de repleção de machos de Metynnis of roosevelti, durante o período de estudo. 
melhores condições alimentares, confirmam os resultados da variação da freqüência relativa dos estádios de repleção e do grau médio de repleção, mesmo tratando-se de informações de caráter qualitativo. Estes resultados podem igualmente ser confirmados pela variação do fator de condição onde é observado que esses parâmetros atingem seus maiores valores no período que antecede à reprodução.

As maiores freqüências de estômagos cheios (grau de repleção III) são observados no bimestre que antecede a época de reprodução, sendo que os valores mínimos ocorrem no período pós-desova (agosto/setembro), para ambos os sexos.

Observa-se uma semelhança na distribuição de estômago parcialmente cheio (grau de repleção I e II) aqueles apresentando grau de repleção III, mostrando estes no entanto, valores superiores. Desta maneira observa-se uma influência bem acentuada no fator de condição com relação ao peso do estômago.

BARBIERI (1981) encontrou estômagos com grau de repleção III nos meses que antecedem a desova de Hoplias malabaricus da Represa do Lobo (São Paulo), corroborando estes resultados com aqueles observados para a espécie em estudo. PAIVA (1974) para a mesma espécie do Nordeste brasileiro encontrou valores elevados do peso do estômago mesmo durante o período de reprodução, confirmando assim a continuidade da atividade alimentar, no período de reprodução.

BARBIERI \& GARAVELLO (1981) constataram para Leporinus friderici Bloch, 1974, que essa espécie encontra-se em melhores condições alimentares no período que antecede à reprodução, diminuindo a atividade alimentar durante a reprodução. Nesse aspecto também há acordo com os dados de GoDOY (1958) que justifica a diminuição da intensidade alimentar na época da reprodução, devido a um aumento do volume das gônadas, principalmente nas fêmeas.

Segundo NIKOLSKI (1963) muitas espécies apresentam alterações da atividade alimentar durante o período reprodutivo. Para o Metynnis cf. roosevelti este processo, que se dá de agosto a dezembro, parece alterar a intensidade alimentar, a despeito de se ter constatado um decréscimo de estômagos com grau de repleção III, no início do período de desova.

Em um trecho alagável do Rio Tocantins, BRAGA (1990) constatou que em algumas espécies, com regimes alimentares diversos, a atividade alimentar é contínua e intensa ao longo do ano, sendo mais pronunciada no período que precede a reprodução, que coincide com a época de seca. Resultados semelhantes foram também obtidos por SANTOS (1979), estudando o comportamento alimentar das espécies Schizodon fasciatus Agassiz, 1829, Rhytiodus microlepis Kner, 1859 no lago do Janaucá (Amazonas), observando que as duas primeiras apresentam grau de repleção mais elevado na estação que antecede o processo de desova. Para a última espécie foi observado comportamento inverso, sugerindo o referido autor, uma decorrência do pequeno número de espécimes amostradas.

\section{REFERÊNCIAS BIBLIOGRÁFICAS}

BARBieri, G. \& J.C. Garavello. 1981. Sobre a dinâmica da reprodução e da nutrição de Leporinus frederici (Bloch, 1974 ) na represa do Lobo, Brotas - 
Itirapina, S.P. (Pisces, Anostomidae). Anais do II seminário Regional de Ecologia, Universidade Federal de São Carlos, p. 347-388.

BARBIERI, M.C. 1981. Contribuição ao estudo da biologia de Gymnotus carapo

(Linnaeus, 1758) na represa do Lobo, Estado de S.P. (Pisces, Ostariophysi,

Gymnotidae). Tese de Doutorado, não publicada, Universidade Federal de São Carlos, São Carlos, 220p.

BRAGA, F.M. DE S. 1990. Aspectos da reprodução e alimentação de peixes comuns em um trecho do rio Tocantins entre Imperatriz e Estreito, Estados do Maranhão e Tocantins. Brasil. Rev. Bras. Biol. 50 (3): 547-558.

Britski, H.A. 1978. Peixes de água doce, p. 84-93. In: CARvalho, J.C.M.

(Ed.). Atlas da fauna brasileira. São Paulo, Ed. Melhoramentos.

BRITSKi, H.A.; Y. SATO \& A.B.S. RosA. 1984. Manual de Identificação de Peixes da Região de Três Marias (com chave de identificação dos peixes da bacia do rio São Francisco). Brasília, Câmara dos Deputados (Coordenação de Publicações - CODEVASF Divisão de Piscicultura e Pesca), 143p.

Eigenmann, C. 1915. The Serrasalminae and Mylinae. Ann. Carneg. Mus., Pittsburg, 9: 226-272.

Godoy, M.P. 1958. Idade, crescimento e peso do peixe. Cien. e Cult. 10 (2): $77-87$

Gulland, J.A. 1971. Manual de métodos para a avaliação das populações de peixes. FAO - Organização das Nações Unidas para Agricultura e Alimentação (Trad. A.E.A. VAzZOLER), 164p.

Gurgel, H.C.B. 1992. Biologia Populacional de Metynnis cf. roosevelti Eigenmann, 1915 (Characidae, Myleinae), da Lagoa Redonda, município de Nízia Floresta, Estado do Rio Grande do Norte. Tese de Doutorado, não publicada, Universidade Federal de São Carlos, 213p.

Nikolsky, G.V. 1963. The ecology of fishes. London, Academic Press, 352p. PAIVA, M.P. 1972. Fisioecologia da traíra, Hoplias malabaricus (Bloch), no Nordeste Brasileiro. Crescimento, resistência à salinidade, alimentação e reprodução. Tese de Doutorado, não publicada, Instituto de Biociências, Universidade de São Paulo, São Paulo.

SANTOS, E.P. 1979. Dinâmica de populações aplicada à pesca e piscicultura. São Paulo, HUCITEC. Ed. Universidade de São Paulo, 129p.

SANTOS, G.M. 1979. Estudos da alimentação, reprodução e aspectos da sistemática de Schizodon fasciatus Agassiz, 1829, Rhytiodus microlepis Kner, 1859 e Rhytiodus argenteofuscus Kner, 1859 do lago Janauacá -AM, Brasil. Tese de Mestrado, não publicada, Fundação Universidade do Amazonas, Manaus, 91p.

Vazzoler, A.E.A. DE M. \& G. Vazzoler. 1965. Relation between condition factor and sexual development in Sardinella aurita (Cuv. \& Val., 1847). An. Acad. Bras. Cienc. 37 (supl.): 353-359. 